\title{
Design of Compact Tri-Band Fractal Antenna for RFID Readers
}

\author{
Mohamed Ihamji ${ }^{1}$, Elhassane Abdelmounim ${ }^{2}$, Hamid Bennis ${ }^{3}$ \\ Mostafa Hefnawi ${ }^{4}$, Mohamed Latrach ${ }^{5}$ \\ ${ }^{1,2}$ LASTI, Faculty of Sciences and Techniques, Hassan $1^{\text {st }}$ University, Settat, Morocco \\ ${ }^{3}$ TIM Research Team, EST of Meknes, Moulay Ismail University, Morocco \\ ${ }^{4}$ Dept. of Electrical and Computer Engineering, Royal Military College of Canada, Canada \\ ${ }^{5}$ RF-EMC research group, ESEO-IETR, Angers, France
}

\begin{tabular}{|c|c|}
\hline Article Info & ABSTRACT \\
\hline & \multirow{5}{*}{$\begin{array}{l}\text { In this paper, a multiband and miniature rectangular microstrip antenna is } \\
\text { designed and analyzed for Radio Frequency Identification (RFID) reader } \\
\text { applications. The miniaturization is achieved using fractal technique and the } \\
\text { physical parameters of the structure as well as its ground plane are optimized } \\
\text { using CST Microwave Studio. The total area of the final structure is } 71.6 \mathrm{x} \\
94 \mathrm{~mm}^{2} \text {. The results show that the proposed antenna has good matching input } \\
\text { impedance with a stable radiation pattern at } 915 \mathrm{MHz}, 2.45 \mathrm{GHz} \text {, and } 5.8 \\
\text { GHz. }\end{array}$} \\
\hline Received Jan 1, 2017 & \\
\hline Revised Mar 20, 2017 & \\
\hline Accepted Apr 4, 2017 & \\
\hline Keyword: & \\
\hline
\end{tabular}

Koch fractal

Microstrip antenna

Miniature antenna

Multiband antenna

RFID

Copyright () 2017 Institute of Advanced Engineering and Science. All rights reserved.

\section{Corresponding Author:}

Mohamed Ihamji,

ASTI Labotary,

Faculty of Sciences and Techniques,

Hassan 1St University, Settat, Morocco.

Email: mihamji@gmail.com

\section{INTRODUCTION}

Radio Frequency Identification (RFID) is the wireless use of electromagnetic field to identify tagged objects and is used in a variety of fields such as access control, transport, banks, health, and logistic. An RFID system is generally composed of a reader and tags. The communication between the reader and the tags is achieved by modulated backscattering of the reader's carrier wave signal. Most RFID systems operate in either the low frequency band $(30-300 \mathrm{kHz})$, the high frequency band (3-30 MHz), the ultra-high-frequency band $(300 \mathrm{MHz}-3 \mathrm{GHz})$, or the microwave band $(3 \mathrm{GHz}-40 \mathrm{GHz})[1-5]$.

One major consideration for handheld and portable RFID reader applications is the compact size. Therefore, the design of miniature reader antennas is important. In this circumstance, fractal antennas are very attractive choice because of their well-known advantages of low profile, lightweight, and easy production. There are many popular fractal geometries, such as the Koch fractal, the Sierpinski fractal, the Hilbert fractal, the Minkowski, and the Square Curve fractals. The Koch fractal microstrip patches are attractive because of their small size and multiband capabilities [6-23].

In this paper, a miniature low cost microstrip multiband antenna, based on the Koch fractal structure, is proposed. Using CST-MW Studio, the antenna is designed and optimized to operate at $915 \mathrm{MHz}$, $2.45 \mathrm{GHz}$, and $5.8 \mathrm{GHz}$ frequencies. 


\section{RESEARCH METHOD}

The proposed antenna is a rectangular radiating patch fed by a $50 \mathrm{ohms}$ microstrip line and uses an FR4 substrate with dielectric constant $\varepsilon_{\mathrm{r}}=4.4$, loss tangent $\tan \delta=0.025$, thickness $\mathrm{H}=1.60 \mathrm{~mm}$, and metal thickness $\mathrm{t}=0.035 \mathrm{~mm}$.

\subsection{Conventional Patch Antenna}

Rectangular patch antenna has two dimensions, the length $\mathrm{L}_{\text {patch }}$ and width $\mathrm{W}_{\text {patch }}$, which are related to the resonant frequency, to the permittivity and to the thickness of substrate by the following conventional equations discussed in [24]:

$$
\begin{aligned}
& W_{\text {Patch }}=\frac{c}{2 f \sqrt{\frac{r+1}{2}}} \\
& L_{\text {Patch }}=L_{\text {eff }} 2 \times L
\end{aligned}
$$

where $\mathrm{c}$ is the speed of light, $\mathrm{f}$ is the resonant frequency and $\varepsilon_{\mathrm{r}}$ is the substrate's dielectric constant $\mathrm{L}_{\mathrm{eff}}$ is the effective length given by:

$$
L_{e f f}=\frac{c}{2 f \sqrt{e f f}}
$$

and $\Delta \mathrm{L}$ is the length extension, given by:

$$
L=0.412 h \frac{\left(e_{\text {eff }}+0.3\right) \times\left(\frac{W}{h}+0.264\right)}{\left(\begin{array}{ll}
\text { eff } & 0.258) \times\left(\frac{W}{h}+0.8\right)
\end{array}\right)}
$$

where, $\mathrm{h}$ is the height of substrate and $\varepsilon_{\mathrm{eff}}$ is the effective dielectric constant which can be determined by:

$$
\varepsilon_{\text {reff }}=\frac{\varepsilon_{r}+1}{2}+\frac{\varepsilon_{r}-1}{2}\left(1+12\left(\frac{h}{W}\right)\right)^{-\frac{1}{2}}
$$

In this case, the dimensions of the conventional patch antenna at frequency $915 \mathrm{MHz}$ are: $\mathrm{L}_{\text {patch }}=76 \mathrm{~mm}, \mathrm{~W}_{\text {patch }}=99 \mathrm{~mm}$.

\subsection{Fractal and Slots Techniques}

Fractals antennas use the space-filling properties to miniaturize the classic antenna elements. The line that is used to represent the fractal can meander to fill the available space. This line is electrically long but compacted into a small physical space [24].

The size reduction of the proposed microstrip antenna is achieved by etching the patch edges according to Koch curve. Multiple iterations of the Koch fractal are shown in Figure 1. To form the first iteration, the original line segment is partitioned into $n=9$ equal line segments of $1 / 5$ the original length. This corresponds to a reduction of $9 / 5$ for the first iteration, $(9 / 5)^{2}$ for the second iteration, and so on.

Three slots are inserted into the patch antenna in order to adjust the other resonances generated by the fractal technique. By this insertion the current is forced to flow through a long path around the slots and change the additional resonance around $2.45 \mathrm{GHz}$ and $5.8 \mathrm{GHz}$.

Figure 2 shows the proposed patch antenna with fractal side of length $\mathrm{L}$ and width $\mathrm{W}$, a microstrip feed line of length $\mathrm{L}_{\mathrm{f}}$ and width $\mathrm{W}_{\mathrm{f}}$, and three inserted slots. The conducting ground plane with length $\mathrm{L}_{\mathrm{gnd}}$, which is placed on the other side of the substrate, is optimized to have a good gain. The width $\mathrm{W}_{\mathrm{f}}$ of the microstrip feed line is fixed at $2.7 \mathrm{~mm}$. 


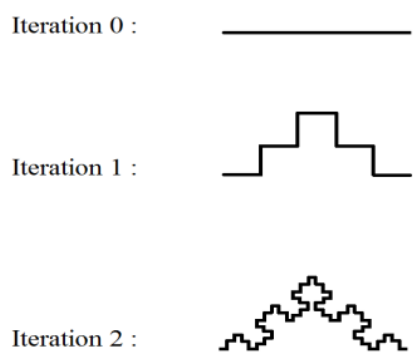

Figure 1. The three iterations of the Koch Curve

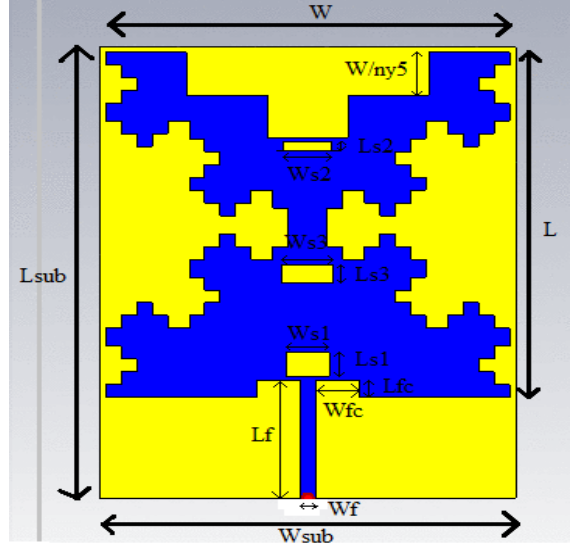

(a)

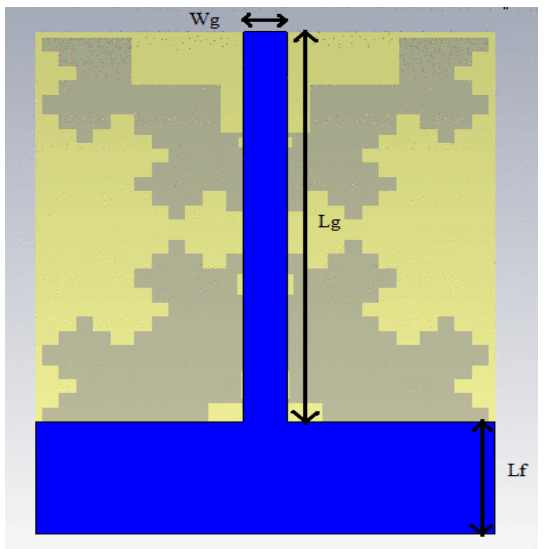

(b)

Figure 2. Geometry of the proposed antenna: (a) Top Face and (b) Back Face

The dimensions of the proposed antenna are presented in Table 1.

\begin{tabular}{cc}
\multicolumn{2}{c}{ TABLE I. Antenna Dimensions } \\
\hline Antenna Dimensions & Optimized Value (mm) \\
\hline $\mathrm{L}$ & 72 \\
$\mathrm{~W}$ & 69.6 \\
$\mathrm{~L}_{\mathrm{sub}}$ & 94 \\
$\mathrm{~W}_{\mathrm{sub}}$ & 71.6 \\
$\mathrm{~L}_{\mathrm{s} 1}$ & 5 \\
$\mathrm{~W}_{\mathrm{s} 1}$ & 7.6 \\
$\mathrm{~L}_{\mathrm{s} 2}$ & 2 \\
$\mathrm{~W}_{\mathrm{s} 2}$ & 8.4 \\
$\mathrm{~L}_{\mathrm{f}}$ & 21 \\
$\mathrm{~W}_{\mathrm{f}}$ & 2.7 \\
$\mathrm{~L}_{\mathrm{fc}}$ & 3.6 \\
$\mathrm{~W}_{\mathrm{fc}}$ & 7.5 \\
$\mathrm{~W}_{\mathrm{g}}$ & 6.8 \\
$\mathrm{~L}_{\mathrm{g}}$ & 73 \\
\hline
\end{tabular}




\section{RESULTS AND ANALYSIS}

\subsection{Simulation Results}

Using the fractal structure and the slots technique to minimize the patch size, we have proposed an antenna structure with fractal side and three slots. The influence of different parameters of the proposed antenna has been studied by using CST simulation software which is based on the Finite Integration Technique. Figure 3, shows the influence of different slots lengths values $\left(\mathrm{L}_{\mathrm{s} 1}, \mathrm{~L}_{\mathrm{s} 2}, \mathrm{~L}_{\mathrm{s} 3}\right)$ to adjust the resonance antenna at $915 \mathrm{MHz}, 2.45 \mathrm{GHz}$ and $5.8 \mathrm{GHz}$. Figure 4 shows the return loss $\mathrm{S}_{11}$ of the proposed antenna after many optimizations, which has good matching input impedance at the three resonant frequencies of $915 \mathrm{MHz}, 2.45 \mathrm{GHz}$, and $5.8 \mathrm{GHz}$. It is also noted that a return loss of less than $-10 \mathrm{~dB}$ was achieved for all three frequencies with a bandwidth varying from $68 \mathrm{MHz}$ to $168 \mathrm{MHz}$.

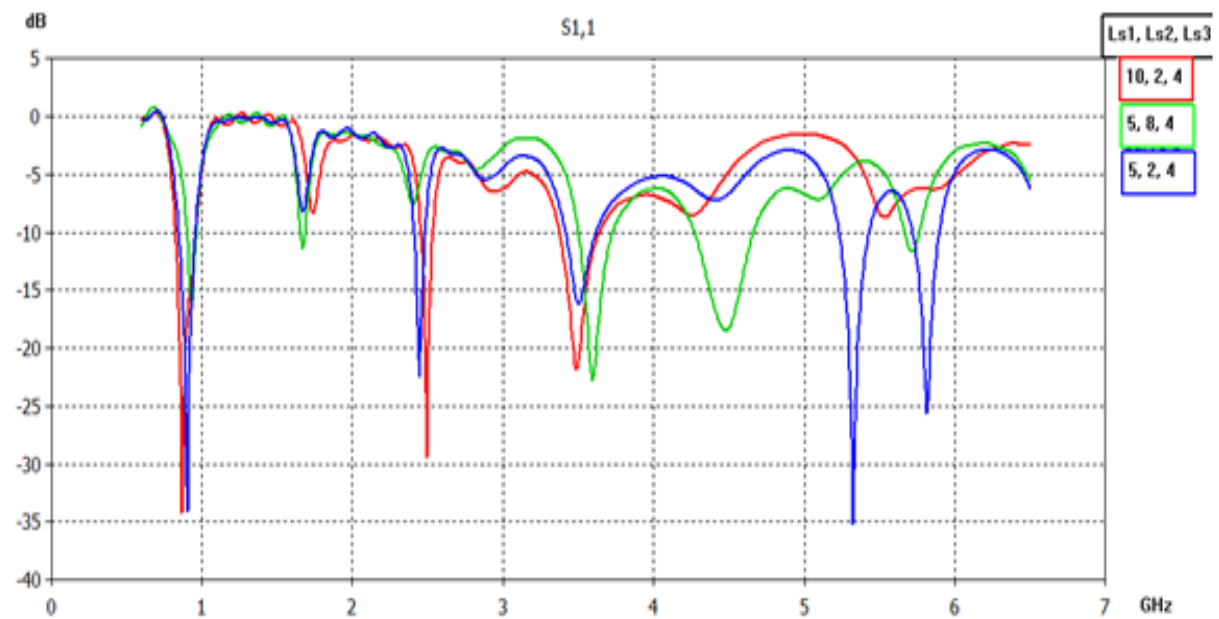

Figure 3. Return loss $S_{11}$ of the proposed antenna with different slots length

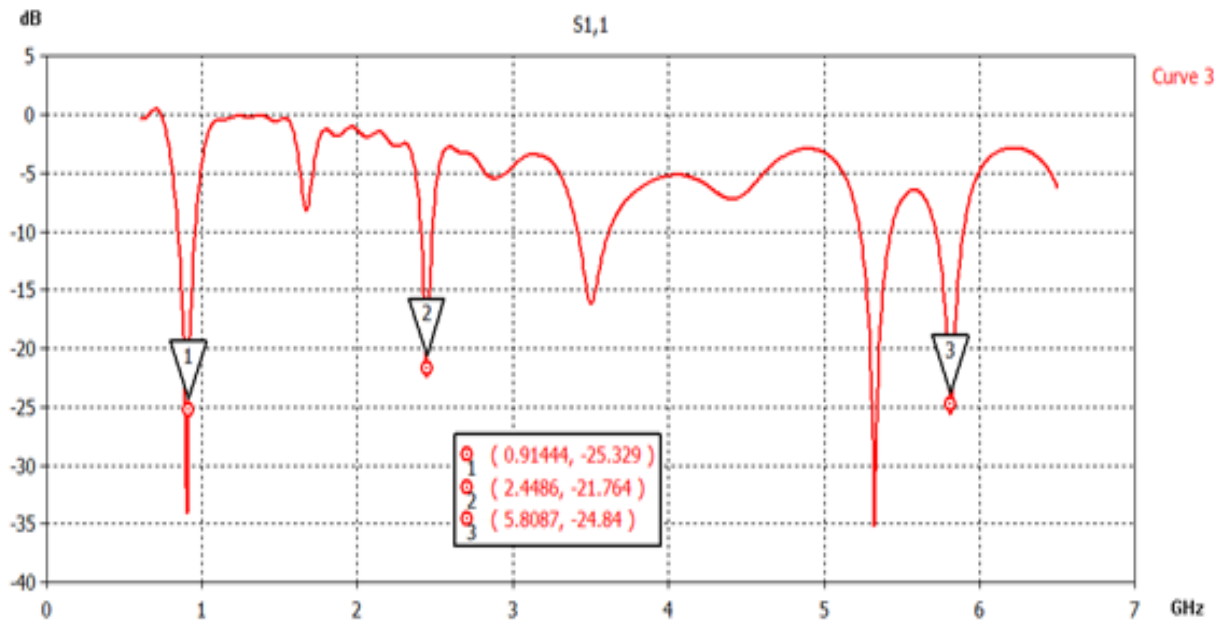

Figure 4. Return loss $S_{11}$ of the proposed antenna

On the other hand, Figure 5 to Figure 7 show the 2D E-plane and H-plane radiation patterns at 915 $\mathrm{MHz}, 2.45 \mathrm{GHZ}$, and 5.8 GHz. The proposed antenna has an omni-directional radiation pattern for both $\mathrm{H}$ plane and E-plane at $915 \mathrm{MHz}$. The angular width is 85 degrees at $915 \mathrm{MHz}, 50.9$ degrees at $2.45 \mathrm{GHz}$, and 27 degrees at $5.8 \mathrm{GHz}$. The achieved bandwidths and gain, which are summarized in Table 2, are very suitable for RFID applications. 


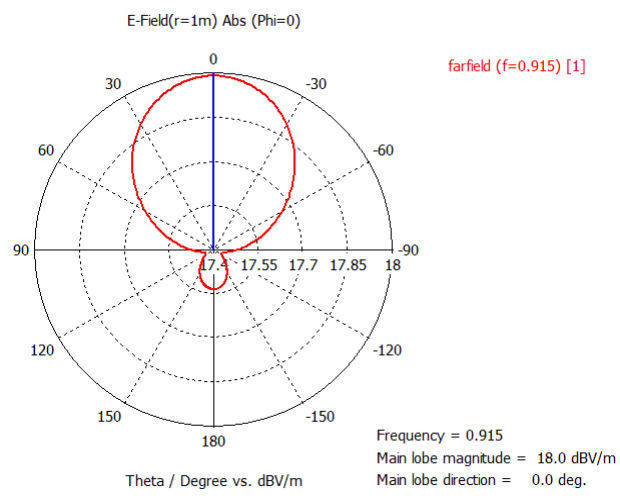

(a)

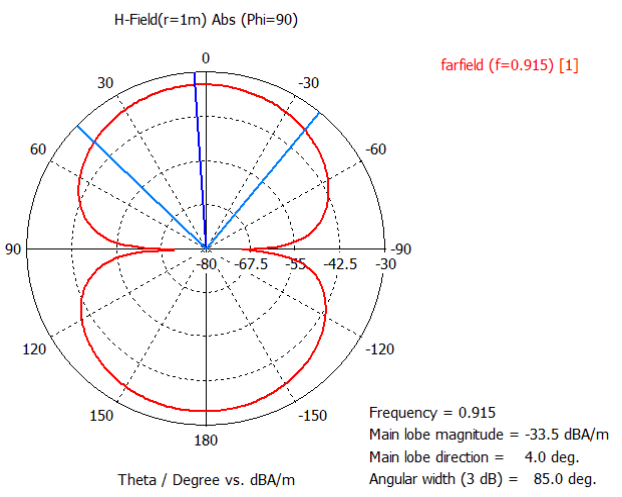

(b)

Figure 5. 2D radiation pattern at $915 \mathrm{MHz}$ in the: (a) E-plane, (b) H-plane

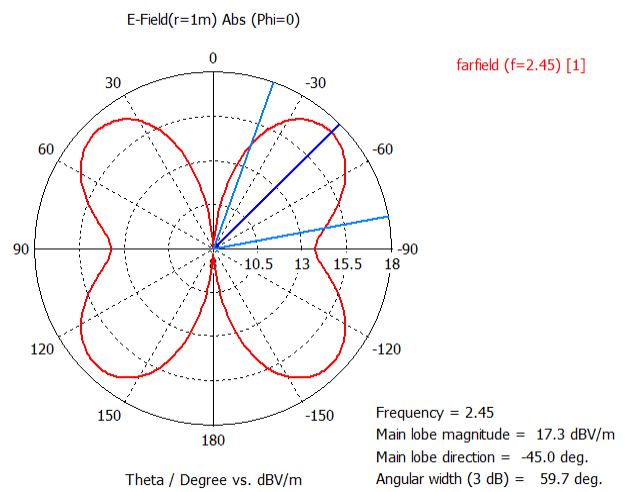

(a)

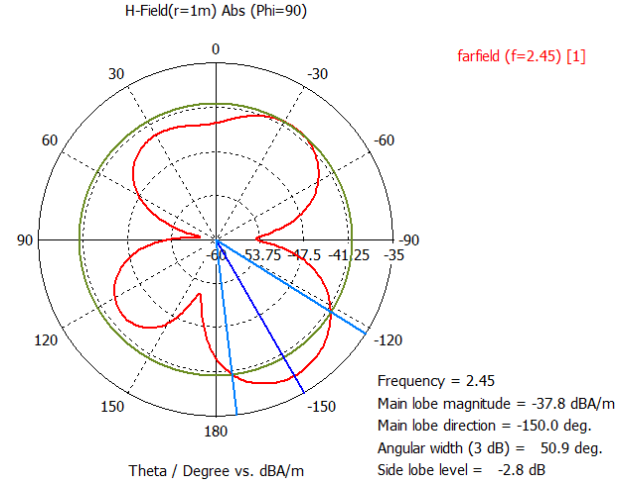

(b)

Figure 6. 2D radiation pattern at $2.45 \mathrm{GHz}$ in the: (a) E-plane, (b) H-plane

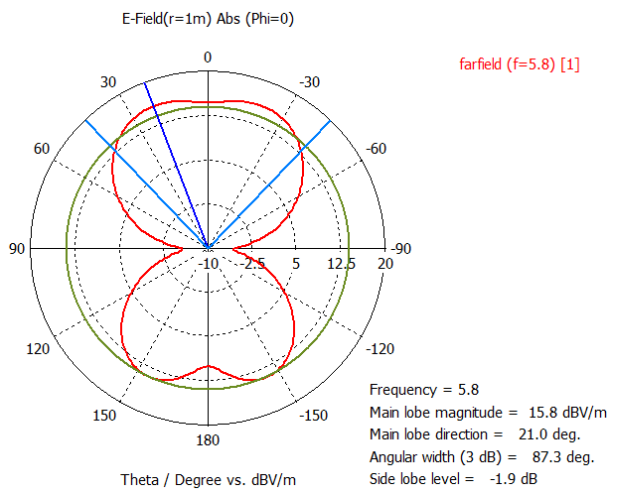

(a)

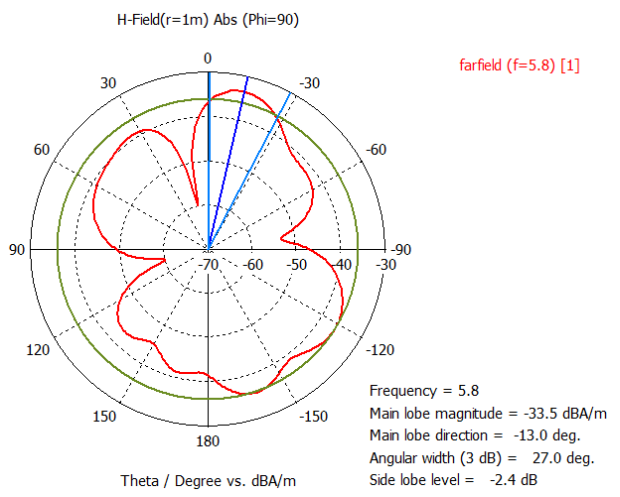

(b)

Figure 7. 2D radiation pattern at 5.8 GHz in the: (a) E-plane, (b) H-plane

Figure 8 and Table 3 compare the size of the proposed patch structure $\left(69.6 \times 72 \mathrm{~mm}^{2}\right)$ with the size of a traditional rectangular patch antenna $\left(99 \times 77.6 \mathrm{~mm}^{2}\right)$ at the same operating frequency of $915 \mathrm{MHz}$. This corresponds to $34.77 \%$ reduction in size. This antenna is also smaller than the fractal antenna proposed in 
[25] which has a size of $72 \times 96 \mathrm{~mm}^{2}$ and has approximately the same FR4 substrate and operates at the same frequency bands $(910 \mathrm{MHz}, 2.4 \mathrm{GHz}$ and $5.8 \mathrm{GHz})$.

Table 2. Performance of the Proposed Antenna

\begin{tabular}{ccccc}
\hline Frequency & S11 (dB) & Bandwidth $(\mathrm{MHz})$ & Gain $(\mathrm{dBi})$ & Directivity $(\mathrm{dBi})$ \\
\hline $915 \mathrm{MHz}$ & -32.9 & 122 & 3.25 & 2.78 \\
$2.45 \mathrm{GHz}$ & -20.1 & 68 & 2.62 & 4.56 \\
$5.8 \mathrm{GHz}$ & -24.6 & 184 & 3.31 & 6.9 \\
\hline
\end{tabular}

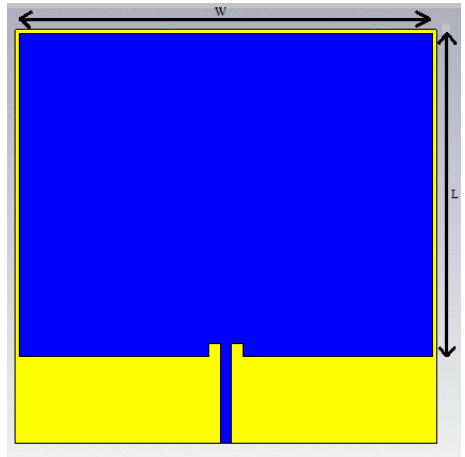

(a)

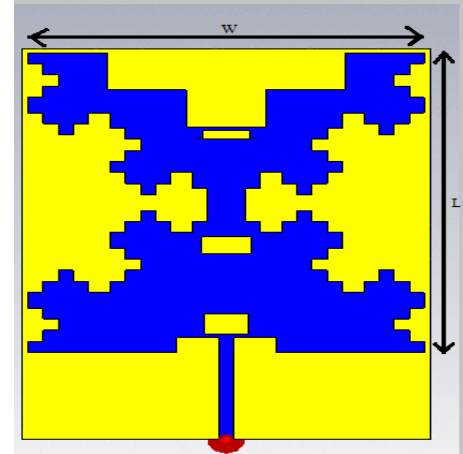

(b)

Figure 8. (a) Ordinary Patch Antenna, (b) Proposed Patch Antenna

Table 3. Patch Antennas Size Comparison

\begin{tabular}{cccc}
\hline Patch Antenna 915 MHz & W (mm) & L (mm) & Patch size reduction (WxL) \\
\hline Conventional Patch Antenna & 99 & 77.6 & \\
Proposed Patch Antenna & 69.6 & 72 & $34.77 \%$ \\
\hline
\end{tabular}

\subsection{Experimental Results}

A prototype of the antenna has been realized as shown in Figure 9.

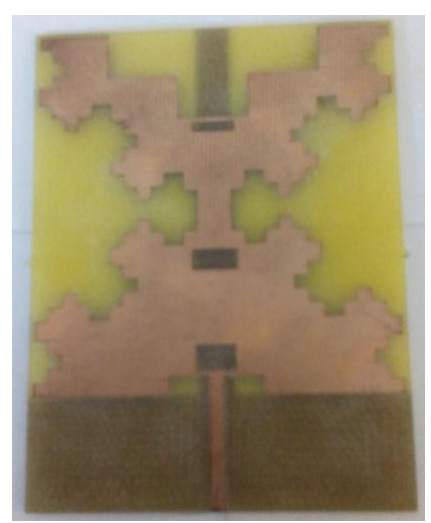

(a)

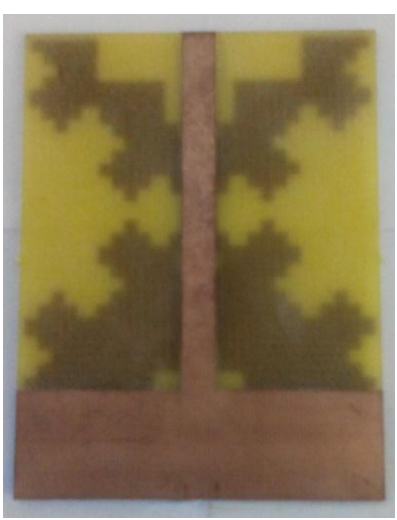

(b)

Figure 9. The antenna prototype achieved: (a) Top Face, (b) Back Face 
Figure 10 compares the simulated and measured return loss of the antenna and the results, which are summarized in Table 4, show good agreement with a return loss of approximately $-10 \mathrm{~dB}$ at the tri-band frequencies of $915 \mathrm{MH}, 2.45 \mathrm{GHz}$, and $5.8 \mathrm{GHz}$.

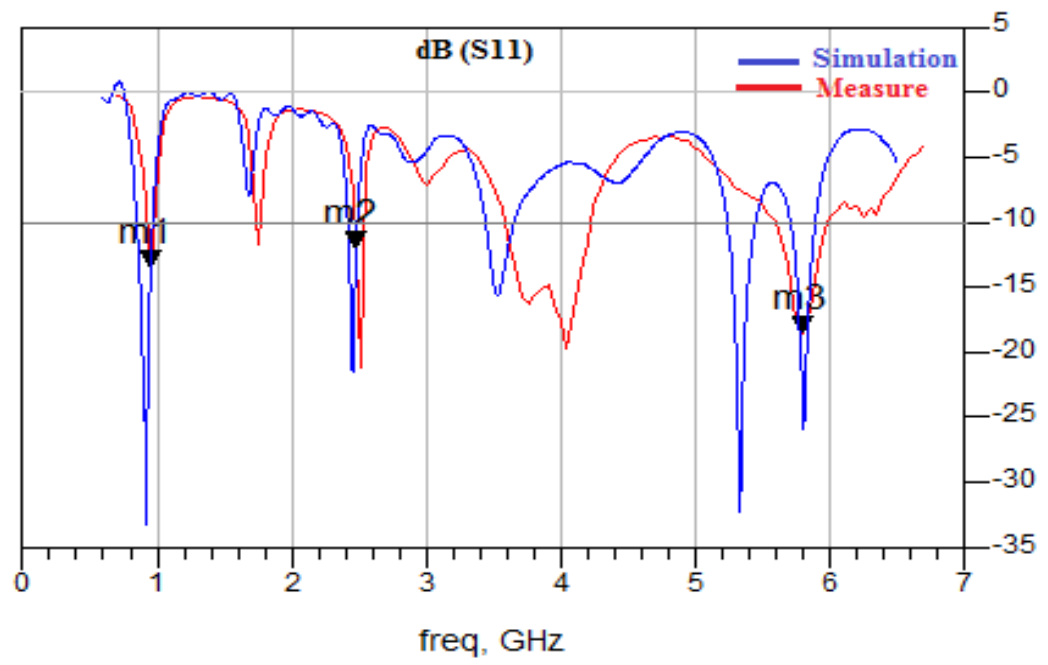

Figure 10. Measured and simulated return loss of the proposed antenna

Table 4. Resume of Simulated and Measured Results

\begin{tabular}{ccccc}
\hline Frequency & S11 $(\mathrm{dB})$ & S11 $(\mathrm{dB})$ & Bandwidth $(\mathrm{MHz})$ & Bandwidth $(\mathrm{MHz})$ \\
\hline & Simulated & Measured & Simulated & Measured \\
$915 \mathrm{MHz}$ & -32.9 & -11.0 & 122 & 52 \\
$2.45 \mathrm{GHz}$ & -20.1 & -10.0 & 68 & 80 \\
$5.8 \mathrm{GHz}$ & -24.6 & -18.6 & 184 & 370 \\
\hline
\end{tabular}

\section{CONCLUSION}

This paper proposed a new tri-band patch antenna for RFID readers. The design was based on fractal structures and slot techniques to achieve a size reduction of $35 \%$ when compared with a conventional rectangular patch. The antenna was designed using a standard FR4 substrate and realized with conventional Printed Circuit Board (PCB) techniques. A return loss of less than $-10 \mathrm{~dB}$ was achieved with a bandwidth varying from52 $\mathrm{MHz}$ to $370 \mathrm{MHz}$ and a gain between $2.62 \mathrm{dBi}$ and $3.31 \mathrm{dBi}$.

\section{ACKNOWLEDGEMENTS}

We gratefully acknowledge Professor Mohamed Latrach for his assistance, guidance and for allowing us to use the experimental equipment of his laboratory.

\section{REFERENCES}

[1] Edited by Nasimuddin, "Microstrip Antennas", Published by InTech Janeza Trdine 9, 51000 Rijeka, Croatia, 2011.

[2] Edited by Debatosh Guha and Yahia M.M, "Microstrip and Printed Antennas: New Trends, Techniques and Applications", Antar_2011 John Wiley \& Sons, Ltd.

[3] Antony Ghiotto, "Thesis Tag UHF RFID Antenna Design, Application by Jet of Material”, Institut Polytechnique Grenoble France, 2008.

[4] Nathan D. Reynolds, "Thesis Long Range Ultra-High Frequency (UHF) Radio Frequency Identification (RFID) Antenna Design", Faculty of Purdue University Fort Wayne, Indiana, 2012.

[5] D.G. Fang, “Antenna Theory and Microstrip Antennas”, by Taylor and Francis Group, LLC, 2010.

[6] Klaus Finkenzeller, "RFID Handbook Fundamentals and Applications in Contactless Smart Cards, Radio Frequency Identification and Near-Field Communication", third edition, Giesecke \& Devrient GmbH, Munich, Germany, 2010. 
[7] Mélusine Pigeon, Thesis, "Design of Ultra-Compact Antennas Based on Metamaterials, Application to the Fabrication of a Miniature GNSS Antenna", Institut National Polytechnique Toulouse France, 2011.

[8] K. Nithisopa, J. Nakasuwan1, N. Songthanapitak, N. Anantrasirichai, and T. Wakabayashi, "Design CPW Fed Slot Antenna for Wideband Applications", Piers online, Vol. 3, No. 7, 2007.

[9] T. Deleruyelle, P. Pannier, E. Bergeret, S. Bourdel, "Dual Band UHF and Microwave RFID Antenna", Proceedings of the 38th European Microwave Conference, 2008.

[10] C. Borja and J. Romeu, "On the Behavior of Koch Island Fractal Boundary Microstrip Antenna", IEEE Transactions on Antennas and Propagation, Vol. 51, pp. 1281-1291, 2003.

[11] A. Reha, A. Elamri, "Fractal Antennas a Novel Miniaturization Technique for Wireless Networks", Transactions on Networks and Communications, Society for Science and Education United Kingdom, Vol. 2, Issue 5, 2014.

[12] G. Monti, L. Catarinucci, and L. Tarricone, "Compact Microstrip Antenna for RFID Applications", Progress In Electromagnetics Research Letters, Vol. (8, 191,199), 2009.

[13] Jithin V M, "Design and Simulation of Microstrip Patch Antenna using ADS", Department of Electrical Engineering, BITS Pilani, Pilani Campus, Rajasthan, India.

[14] Nazish Irfan, Mustapha C. E. Yagoub, and Khelifa Hettak, "Design of a Microstrip-line-fed Inset Patch Antenna for RFID Applications", IACSIT International Journal of Engineering and Technology, Vol. 4, No. 5, 2012.

[15] S.Anscy, "Slot Microstrip Antenna for 2.4GHz RFID Reader Application", Department of Electronics and Communication Engineering Karunya University, International Journal of Advanced Research in Electronics and Communication Engineering (IJARECE), Volume 2, Issue 5, 2013.

[16] Mohamed Ihamji, Elhassane Abdelmounim, Jamal Zbitou, Hamid Bennis, Mohamed Latrach, "Novel Design of a Miniature L-Slot Microstrip CPW-Fed Antenna for RFID Reader", IEEE Conference Publications, the 11th International Conference on Intelligent Systems: Theories and Applications (SITA), 2016.

[17] Mohamed Ihamji, Elhassane Abdelmounim, Jamal Zbitou, Hamid Bennis, Mohamed Latrach, "Novel Design of a Miniature Fractal Microstrip CPW Fed Antenna for RFID Reader", IEEE Conference Publications, the International Conference on Wireless Networks and Mobile Communications (WINCOM), 2016.

[18] Chaouki Guesmi, Abdelhak Ferchichi, Ali Gharsallah, "A Modified Fractal Bow Tie Antenna for an RFID Reader", International Journal of Electrical and Computer Engineering (IJECE), Vol. 4, No. 3: June 2014.

[19] Abdelhak Ferchichi, Gharsallah Ali, “A Novel small Sierpenski Antennas”, International Journal of Electrical and Computer Engineering (IJECE), Vol 3, No 4: August 2013.

[20] Anas Sofi, Khalid Roky, Ibrahim Hadj Baraka, "Antenna Design for UHF RFID Tags Using Two Coupled Patches", International Journal of Information and Network Security (IJINS), Vol 3, No 1 (2014).

[21] Anas Sofi, Khalid Roky, Mohammed Bouhorma, Ibrahim Hadj Baraka, "Novel Antennas for UHF RFID Tags: Design and Miniaturization", International Journal of Electrical and Computer Engineering (IJECE), Vol 4, No 1: February 2014.

[22] Loubna Berrich, Lahbib Zenkouar, "Microruban Dipole Antenna for RFID Applications at 2.45 GHz", International Journal of Electrical and Computer Engineering (IJECE), Vol 6, No 6: December 2016.

[23] Xue Jian-bin, He Fengjie, Wang Dong, "Analysis and Design of Tag Antenna Based UHF RFID for Libraries", Indonesian Journal of Electrical Engineering and Computer Science (IJECS), Vol 13, No 3: March 2015.

[24] A. Balanis, “Antenna Theory Analysis and Design”, 2nd edition (John Wiley \& Sons, Inc., 2003).

[25] Aidin Mehdipour, Iosif D. Rosca, Abdel-Razik Sebak, Christopher W. Trueman, Suong. V. Hoa, "Full-composite Fractal Antenna using Carbon Nanotubes for Multiband Wireless Applications", IEEE Antennas and Wireless Propagation Letters, Volume 9, 2010.

\section{BIOGRAPHIES OF AUTHORS}

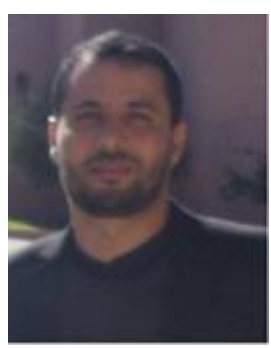

Mohamed Ihamji was born in Casablanca, Morocco. He received the diploma in electronics engineering from ENSI Caen, France, in 2006. From 2006 to 2011 he worked as development engineer for RFID application. Currently he is working towards his Ph.D. His current research activities are focused on RFID antennas.

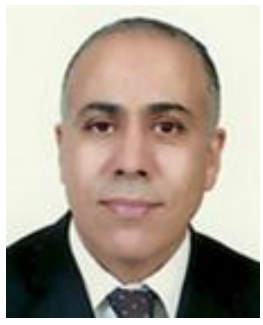

Elhassane Abdelmounim was born in Oued-Zem Morocco in 1965, he received his $\mathrm{PhD}$ in Spectral analysis from Limoges University France in 1994. In 1996, he joined, as Professor, applied physics department of FST, Hassan I University, Settat, Morocco. His current research interests include digital signal processing and machine learning. He is currently coordinator of a Bachelor of Science in electrical engineering and he is researcher at System Analysis and Information Technology Laboratory at Hassan I University, Settat, Morocco. 


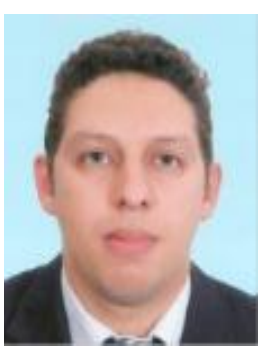

Hamid Bennis was born in Meknes, Morocco, in September 1977. He received the Ph.D. degree in Computer Science and Telecommunications from the University of Mohammed V Agdal, Rabat, Morocco, in 2011. He is currently a Professor of Computer Science and Telecommunications in EST of Meknes, University of Moulay Ismail, Morocco. He is involved in the design of hybrid, monolithic active and passive microwave electronic circuits.

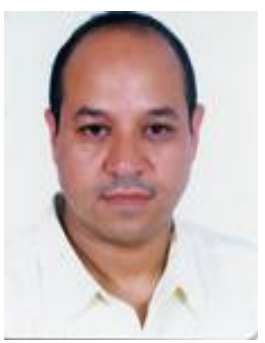

Mostafa Hefnawi is currently a professor and the Chair of Graduate Studies Committee in the Department of Electrical and Computer Engineering at the Royal Military College of Canada. Dr. Hefnawi is a licensed professional engineer in the province of Ontario. He is a contributing author of a number of refereed journal, book chapters, and proceeding papers in the areas of wireless communications. His research interest includes cognitive radio, wireless sensor network, massive MIMO, cooperative MIMO, multiuser MIMO, and smart grid communications

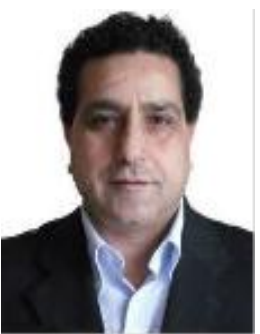

Mohamed Latrach (Member of IEEE and URSI-France) received the Ph.D. degree in electronics from the University of Limoges, Limoges, France. He is currently Professor of microwave engineering in the Ecole Supérieure d'Electronique de l'Ouest (ESEO), Angers, France, where he is Head of the RF-EMC research group. His research interests include: design of hybrid \& monolithic active and passive microwave circuits, metamaterials, LH materials, antennas, rectennas and their applications in wireless communications, wireless power transmission (WPT), sensors connected objects, etc. Mohamed LATRACH has supervised several PhD, postdoctoral and master/engineer students, with many publications in national and international conferences and journals. He has also holds 3 patents. He serves as a reviewer for various journals and congress. He has delivered numerous invited presentations and has participated in many projects. 